УДК 659.2

\section{В.А. Жуков}

Vadim Zhukov

\section{СОВРЕМЕННЫЕ ТЕНДЕНЦИИ РАЗВИТИЯ РЫНКА КОНСАЛТИНГОВЫХ УСЛУГ}

Аннотация. В статье проанализированы этапь функционирования рынка консалтинговых услуг, определены критерии классификации всего спектра консалтинговых компаний и исследованы особенности деятельности каждого выделенного вида организацчий. Сделана сегментация потребителей консалтинговых услуг. Рассмотрень ассочиации консультантов и консалтинговых агентств и их функции. Выявлены тенденции развития мирового рынка консалтинговых услуг: привлечение разнообразных консультантов; борьба за квалифицированный персонал; внедрение современных информационных технологий; ориентация на здравоохранительную отрасль; формирование новых моделей консультирования.

Ключевые слова: консалтинг, консалтинговая услуга, менеджмент, маркетинг, финансы.

\title{
MODERN TRENDS OF DEVELOPMENT OF THE CONSULTING SERVICES MARKET
}

\begin{abstract}
Annotation. In the article the stages of the functioning of the consulting services market are analyzed, the criteria for classifying the entire spectrum of consulting companies are determined and the features of the activity of each selected type of organization are investigated. The segmentation of consumers of consulting services was done. The associations of consultants and consulting agencies and their functions are considered. The tendencies of development of the world market of consulting services are revealed: attraction of various consultants; fight for qualified personnel; introduction of modern information technologies; orientation on the healthcare industry; formation of new models of counseling. Keywords: consulting, consulting services, management, marketing, finance.
\end{abstract}

В настоящее время спрос на консалтинговые услуги растет, что обусловлено развитием бизнеса и необходимостью повышения эффективности его работы. Специалисты считают, что существует два подхода к определению консалтинговых услуг: широкий и узкий. Согласно широкому функциональному подходу, консалтинг понимается как совокупность практических советов и помощи. Представителями широкого подхода являются Ф. Стееле и П. Блок. Ф. Стееле определяет консалтинг как любую форму оказания помощи вотношении содержания, процесса или структуры задачи или серии задач, при которой консультант сам не отвечает за выполнение задачи, но помогает тем, кто несет за нее ответственность [1; 5].

В рамках узкого профессионального подхода консалтинг рассматривается как профессиональная служба. Представителями данного подхода являются Л. Грейнер и Р. Метцгер. Они понимают управленческое консультирование как консультативную службу, работающую по контракту и оказывающую услуги организациям с помощью квалифицированных специалистов, которые помогают организации-заказчику выявить управленческие проблемы, проанализировать их, дать рекомендации по их решению ипри необходимости содействовать выполнению этих решений $[2 ; 3]$.

(C) Жуков В.А., 2017 
Причины, по которым клиенты обращаются за консалтинговыми услугами, сводятся к следующему: клиенты хотят получить помощь или совет по вопросам менеджмента, в вопросах повышения эффективности труда, сокращения издержек. Консалтинговые услуги могут касаться как общих вопросов менеджмента (планирование, отчетность, повышение эффективности контроля, оптимизация бизнес-процессов), так и конкретных направлений менеджмента (финансы, маркетинг, управление человеческими ресурсами, производство) [4].

Очень часто перед собственниками или руководством компаний стоит вопрос: нанять специалиста по развитию бизнеса в штат или пригласить внешнего консультанта. Основное отличие внутреннего специалиста от внешнего заключается в том, что консультант не несет ответственности за свои рекомендации, а также не участвует в практической реализации данных им советов. Еще одно отличие представителей консалтинговых фирм от менеджеров компаний заключается в том, что они лишь дают резюме своих наблюдений, а принятие решений и обеспечение их исполнения лежит уже на руководстве компании или на линейных менеджерах.

Консалтинговые услуги как отрасль имеют богатую историю развития. Впервые они появились в конце XVIII в. и с тех пор прошли ряд значительных этапов в своем становлении. Первые консультанты появились в ходе развития промышленной революции, когда возникли первые фабрики и произошло большое количество институциональных изменений. Во второй половине XIX в. консультирование обычно концентрировалось на вопросах управления производством и повышении эффективности труда, а также на сокращении издержек. Первым консультантом можно назвать обувного фабриканта Ч. Сэмпсона, который передавал свой опыт многим другим промышленникам [1]. Именно в это время появилась концепция научного управления производством. В это же время появились первые фирмы, оказывавшие консалтинговые услуги по различным вопросам, в том числе производственным. Появились первые профессиональные консультанты, среди которых можно выделить Ф. Тейлора, А. Д. Литтл, Т. Пэррин и Г. Эмерсона [5].

Второй этап в развитии консалтинговых услуг - период с 1910 г. по 1930 гг. - характеризуется тем, что объектом консультирования стал общий менеджмент, а не только лишь производство. В 1914 г. Э. Вуз организовал службу деловых исследований- «Буз-Ал-лен энд Хамилтон», а в 1925 г. Дж. МакКинси и Э. Карни основали компанию, давшую впоследствии начало двум крупнейшим в мире консультационным фирмам - «МакКинси энд компани» и «А. Т. Карни». Стоит заметить, что «МакКинси энд компани» была первой компанией, начавшей консультирование по вопросам финансового менеджмента. В этот же период была основана Ассоциация фирм по управленческому консультированию (далее - АCME).

Третий этап - с 1930 г. до начала 1950-х гг. Этот период по праву называют «золотым веком управленческого консалтинга». В этот период бизнес по оказанию консалтинговых услуг приобрел репутацию быстрорастущего и высокомаржинального, что способствовало увеличению количества отраслей, обслуживаемых консалтинговыми компаниями. В свою очередь, появление большого числа новых фирм обуславливалось растущим спросом на услуги консультантов. Помимо количественного роста фирм, значительно расширяется и спектр предоставляемых услуг, повышается их качество. Если характеризовать маркетинговые стратегии компаний, то в основном в силу бурного развития отрасли они носили агрессивный характер.

Четвертый этап развития (1960-1980-е гг.) консалтинга характеризуется выходом направления на новый, международный уровень. Формируется так называемая «большая восьмерка» консалтинговых компаний: Arthur Andersen, Arthur Young, Cooper and Lybrand, Deloitte Haskings and Sells, Ernst and Whinney, Peat, Marwick, Mitchell, Price Waterhouse, Touche Ross. В этот период развивается внутрифирменное консультирование, растет профессиональная компетенция консультантов. Вместе с тем консультирование по-прежнему носило «стихийный характер», а именно: отсутствовали правила и нормы поведения кон- 
сультантов, имело место распространение конфиденциальной информации. По сравнению с современной эпохой консалтинговые услуги были довольно низкого качества, при этом консультантами работали только мужчины. Как правило, консультанты работали всего 2-3 года, после чего они переходили на работу в другую отрасль. В то же время возрастали требования клиентов к компетентности консультантов.

Пятый этап развития консалтинговых услуг (1990-е гг.) характеризуется еще большим расширением спектра предоставляемых услуг. Консалтинговые компании стали узкоспециализированными: либо по отрасли экономики, либо по функциональным отраслям менеджмента. В этот период появилось более 30-ти новых компаний, осуществлявших деятельность на международном уровне. Кроме того, новым направлением деятельности компаний стало использование информационных технологий, что было связано с бурным развитием автоматизации и высоких технологий. В целом данный этап характеризовался определенным насыщением рынка и стагнацией. Стагнация была обусловлена во многом замедлением темпов роста мировой экономики и снижением деловой активности, особенно в развитых странах.

Рост в консалтинговой отрасли начался только после 2003 г. Этот период ознаменовался значим событием - обанкротилась компания Arthur Andersen. Эта компания, наряду с Ernstand Young, KPMG, Deloitte, $\mathrm{PwC}$, входила в «большую пятерку» компаний, осуществляя деятельность в более чем 80 странах и имея доходы в 2002 г. 9,3 млрд долл. США [7]. К краху компании привело банкротство компании Enron, чьим аудитором как раз и являлась компания «Arthur Andersen». Как оказалось, руководство Enron было замечено в финансовых махинациях и сокрытии огромных убытков. Arthur Andersen обвинили в халатном отношении к проверке финансовой отчетности и умышленном сокрытии фактов. После этого были осуществлены проверки в других компаниях-клиентах ArthurAndersen, после чего многие из них прекратили свою деятельность.

Банкротство компаний негативно сказалось на образе и репутации как всей консалтинговой отрасли, так и компаний «большой четверки». В обществе возникло определенное недоверие к поставщикам консалтинговых услуг. С другой же стороны, банкротством Arthur Andersen воспользовались другие компании, поскольку клиенты Arthur Andersen стали клиентами других аудиторских компаний. Наибольшую выгоду извлекла компания Ernstand Young - еe выручка выросла на 29,8 \% за 2002-2003 гг. [6].

В настоящее время рынок консалтинговых услуг характеризуется достаточно высокими темпами роста, особенно высокими являются темпы роста в Европе. В европейских странах темпы роста консалтинговой отрасли за 2014-2016 гг. значительно превысили темпы роста внутреннего валового продукта (далее - ВВП) за тот же период (см. табл. 1) [10].

Таблица 1

\section{Динамика рынка консалтинговых услуг в Европе}

\begin{tabular}{|l|l|l|l|l|}
\hline & 2013 г. & 2014 г. & 2015 г. & 2016 г. \\
\hline Прирост, \% & 3,8 & 5,2 & 6,5 & 6,9 \\
\hline $\begin{array}{l}\text { Рост ВВП } \\
\text { в европейских странах, \% }\end{array}$ & 0,6 & 3,4 & 1,5 & 1,6 \\
\hline
\end{tabular}

Еще одной тенденцией развития рынка консалтинговых услуг является то, что спектр услуг консалтинговых компаний увеличивается. Если раньше компании специализировались на вопросах производственного менеджмента или стратегического управления, то в настоящее время практически невозможно найти узкоспециализированные компании, занимающие определенные ниши. С другой же стороны, проблемы у бизнес-компаний тоже носят многоплановый характер - им требуется по- 
мощь специалистов из разных сфер деятельности. С этой целью в рамках консалтинговых компаний формируются проектные команды, куда входят специалисты из разных областей менеджмента.

Ввиду высокого спроса на консалтинговые услуги, растет число поставщиков этих услуг. Все компании, занимающиеся консалтингом, можно квалифицировать следующим образом:

- в зависимости от размера и масштаба деятельности компаний: крупные компании («большая четверка»), работающие по всему миру, средние и мелкие компании (работают в одной стране или определенном регионе страны), компании, состоящие из одного или нескольких человек (зачастую такие консультанты совмещают основную деятельность с преподаванием в вузах и на специализированных курсах);

- в зависимости от сферы деятельности: компании, занимающиеся только консалтингом (большинство компаний в настоящее время), компании, занимающиеся консалтингом и аудитом («большая четверка»), компании, занимающиеся консалтингом и научным менеджментом, например, разработкой новых теорий («фабрики мысли» - Bain \& Co, McKinsey, BCG);

- предметно-ориентированные компании, занимающиеся только определенными вопросами менеджмента (маркетинг, управление персоналом или финансовый менеджмент).

Рассмотрим некоторые группы компаний более подробно.

К компаниям «большой четверки», как уже было сказано, относятся следующие компании: Ernstand Young, Deloitte, KPMG, PwC. Эти компании были созданы много лет назад. Их деятельность состоит из двух главных направлений: аудит и консалтинг. Если говорить о консалтинге, то они занимаются практически всеми направлениями. Данные компании обладают наибольшим авторитетом и самой прочной репутацией в мире. Их клиентами являются крупнейшие мировые транснациональные корпорации (далее - ТНК). Как результат - высокая стоимость услуг и не менее высокая степень престижности работы в этих компаниях. Также у этих компаний самая высокая выручка на рынке консалтинговых услуг. Совокупный доход компаний насчитывает более 100 млрд долл. США ежегодно. Если сравнивать компании между собой по уровню выручки, то наибольшим объемом обладают компаний Deloitte и PwC. Выручка EY и KPMG ниже в среднем на 20-25 \%. На рис. 1 показана выручка компаний за последние 3 года (в млрд долл. США) [7].

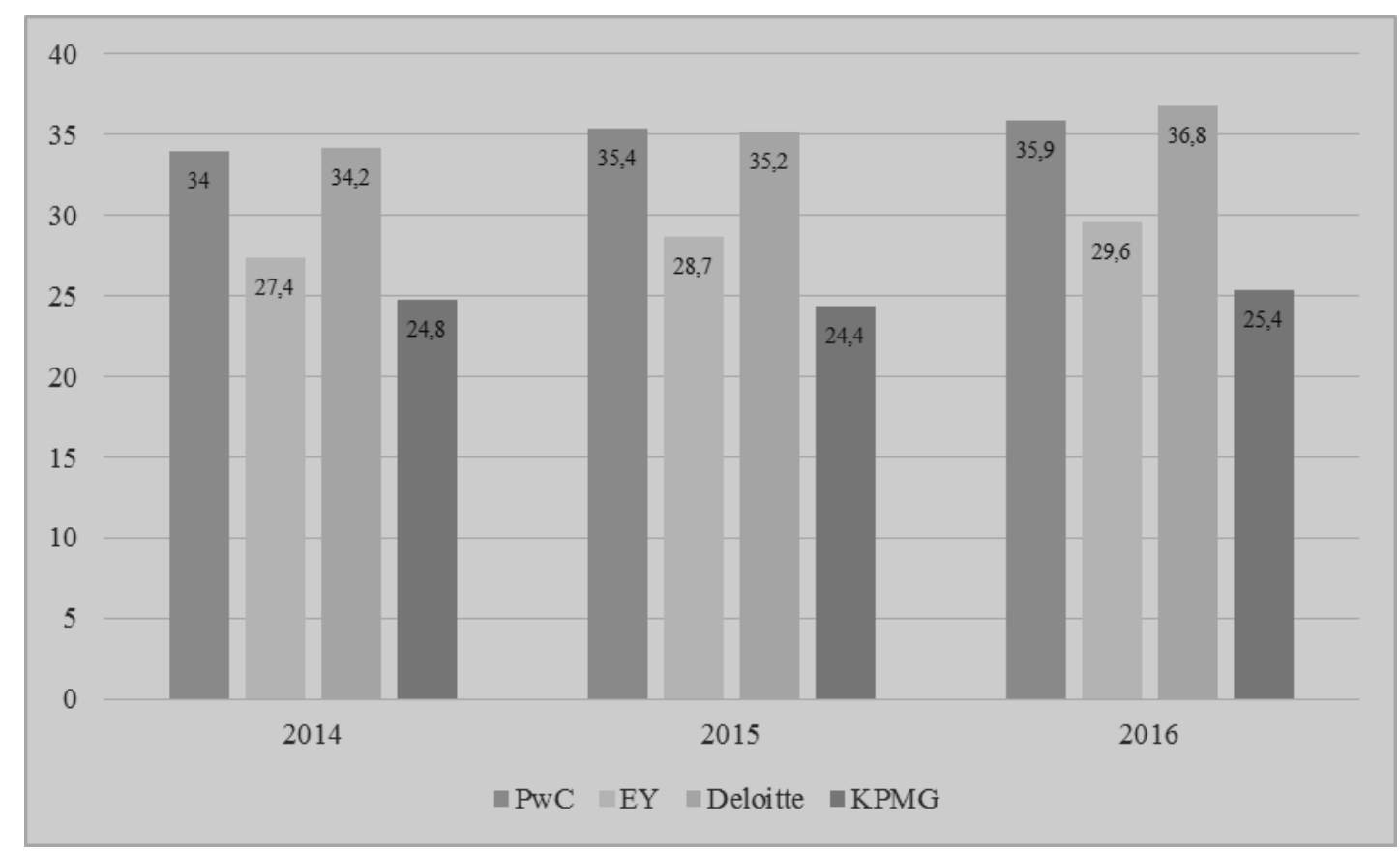

Рис. 1. Выручка компаний «большой четверки» (млрд долл. США) 
Анализ табл. 2 показывает, что консалтинг занимает практически треть оказываемых компаниями услуг. Такая тенденция сохраняется на протяжении уже нескольких лет и, скорее всего, в дальнейшем будет только усиливаться.

Таблица 2

Доходы каждой компании «большой четверки» за 2016 г. [7]

\begin{tabular}{|l|l|l|l|l|}
\hline \multicolumn{1}{|c|}{ Услуга Компания } & PwC & Deloitte & KPMG & EY \\
\hline $\begin{array}{l}\text { Аудиторские услуги, млрд } \\
\text { долл. США }\end{array}$ & 15,3 & 9,4 & 10,12 & 11,3 \\
\hline $\begin{array}{l}\text { Налоговые и юридические } \\
\text { услуги, млрд долл. США }\end{array}$ & 9,1 & 6,9 & 5,56 & 10,5 \\
\hline $\begin{array}{l}\text { Консультационные услуги, } \\
\text { млрд долл. США }\end{array}$ & 11,5 & 20,5 & 9,74 & 7,8 \\
\hline
\end{tabular}

Второй группой консалтинговых компаний являются так называемые «фабрики мысли». Называют их так потому, что они не просто оказывают консалтинговые услуги, но и предлагают найти необычный и нестандартный выход из ситуации, предлагая креативные идеи. В этой группе следуют выделить такие компании, как McKinsey, BostonConsultingGroup, Bain\& Co. Эти компании формируют так называемую «большую тройку» консалтинговых компаний, специализирующихся на стратегическом управлении.

Отличиями компаний «большой тройки» от «большой четверки» является то, что они предоставляют услуги лишь в области консалтинга, не занимаясь вопросами аудита и оптимизации налогообложения. Помимо этого, их масштабы деятельности гораздо меньше: как по числу занятых, по числу открытых офисов, так и по обороту (их совокупная выручка практически в 10 раз меньше, чем выручка крупнейших аудиторских компаний). Наконец, количество клиентов «большой тройки» гораздо меньше, чем у крупнейших консалтинговых компаний, и одновременно данные клиенты, как правило, являются менее крупными и известными компаниями. Таким образом, можно сделать вывод, что «большая тройка» работает с теми, кто по каким-либо причинам не работает с «большой четверкой».

Следующая группа компаний - это предметно-ориентированные компании, чья деятельность ограничивается одним или несколькими направлениями, например, маркетинговыми исследованиями, подбором персонала или составлением бизнес-планов. Численность таких компаний - самая высокая.

Если посмотреть на структуру выручки консалтинговых компаний, то можно заметить, что традиционно львиная доля приходится на IT и управленческий консалтинг. Такая ситуация характерна не только для России, но и для большинства развитых стран. Связано это, во-первых, с бурным развитием новых технологий и большой потребностью в автоматизации систем управления компаний. Во-вторых, высокий спрос на управленческий консалтинг связан с увеличением сложности проблем, с которыми сталкиваются руководители малых и средних предприятий - именно они являются целевой аудиторией таких компаний. Спрос на управленческий консалтинг также обусловлен тем, что довольно часто руководству таких компаний не хватает опыта в разрешении стоящих перед ними проблем. Помимо этого, ввиду изменчивости внешней среды, менеджмент не в состоянии разобраться, как внедрять IT, поэтому и вынужден обращаться к внешним специалистам.

Наконец, на рынке существуют небольшие консалтинговые компании, состоящие из одного или нескольких специалистов, причем некоторые из них совмещают эту работу с преподаванием в вузах. Иногда компании обращаются к индивидуальным консультантам, которые либо имеют свой бизнес, либо ведут научную деятельность, делясь опытом с другими компаниями в качестве 
внешнего консультанта. Такая практика, зародившаяся в США, распространилась и в Европе, а также последнее время набирает обороты в России.

Плюсами работы с указанными выше двумя последними группами консалтинговых компаний является то, что стоимость их услуг невелика, а также то, что они за счет специализации на одной конкретной отрасли имеют высокий уровень компетенции. Обратной стороной сотрудничества с ними может быть то, что если требуется работа по вопросам, которые выходят за рамки их специализации, они могут дать неверную оценку ситуации. Кроме того, уровень их квалификации может оказаться невысоким из-за небольшого опыта работы и высокого уровня сложности проблем, с которыми им придется столкнуться.

Говоря о консалтинговых компаниях, нельзя не упомянуть интеграционные объединения, которые происходят на рынке консалтинговых услуг. Существуют профессиональные ассоциации консультантов и консалтинговых агентств. Старейшими из них являются: ACME, Международный совет институтов управленческого консультирования (далее - ICMCI) и Европейская федерация ассоциаций консультантов по вопросам управления (далее - FEACO).

ICMCI был основан в 1987 г. и представляет собой сеть ассоциаций консультантов по всему миру, которая имеет общую миссию, ценности и цели. Целью ICMCI является поощрение тесного взаимодействия между консалтинговыми организациями, которое, в свою очередь, направлено на выработку единых стандартов деятельности консалтинговых организаций. В настоящее время в ICMCI входит 48 стран [9].

FEACO является международной некоммерческой организацией, которая была образована в 1966 г. В ее состав входят ассоциации большинства европейских стран, которые представляют более 3000 консалтинговых компаний. Основная цель организации - содействие развитию и продвижению консалтинговых услуг в мире. Функциями организации являются:

- развитие рынка управленческого консалтинга;

- повышение статуса консалтинга на международном уровне благодаря продвижению общепринятых профессиональных этических стандартов и стандартов качеств;

- осуществление тесного взаимодействия с европейскими институтами и другими международными организациями для обеспечения информированности и защиты профессиональных интересов;

- организация пространства для активного общения с целью установления различных связей и повышения уровня сервиса;

- поощрение установления связей между членами различных ассоциаций, осуществляемое посредством спонсорства и организации конференций, встреч и рабочих групп по общим интересам (тематика этих мероприятий: оценка качества консалтинговых услуг, организация обмена опытом и т.д.) [8].

Членство в FEACO дает возможность организациям-членам влиять на принимаемые в рамках организации решения, возможность установления контактов с коллегами из других стран и поиск партнеров. Нельзя не отметить, что для малых и средних компаний быть членом FEACO - почетно. Членство в FEACO может быть использовано как конкурентное преимущество при продвижении услуг. В то же время нельзя не отметить тот факт, что «большая четверка» не входит в FEACO. Связано это с тем, что они обладают большей известностью и авторитетом на рынке консалтинга и, таким образом, не нуждаются в «членстве ради членства». Кроме того, скорее всего, они не видят для себя весомых преимуществ и выгод в связи с большей масштабностью деятельности: они работают по всему миру, в то время как FEACO - лишь европейская организация.

Организация ACME, в отличие от FEACO, работающей в Европе, функционирует в Северной Америке. АСМЕ была образована первоначально в 1929 г., но затем ее деятельность была прекращена и восстановлена лишь в 1972 г. Данная Ассоциация объединяет консалтинговые компании североамериканского континента. Специфика ее деятельности (в сравнении с FEACO) состоит в том, что ее членами являются крупнейшие американские консалтинговые фирмы, имеющие филиалы практически во всех регионах мира. Обе эти организации приняли кодексы этики, согласно которым компа- 
нии ставят интересы заказчика выше своих собственных интересов. Кроме того, они декларируют, что консалтинговые компании не должны совершать действий, которые могут повредить репутации управленческого консалтинга, обязуются соблюдать конфиденциальность, быть транспарантными и обеспечивать высокое качество оказываемых услуг.

Помимо профессиональных консалтинговых ассоциаций существуют также организации, в которых консультанты включаются наряду с другими специалистами в области менеджмента: преподавателями, профессиональными менеджерами и т.д. К таким организациям относятся Евр опейский фонд развития менеджмента (EFMD), Ассоциация развития менеджмента стран Центральной и Восточной Европы (CEEMAN), Американская ассоциация менеджмента (AMA), Японская федерация менеджмент-организаций (ZEN-NOH-REN).

Одна из важных особенностей рынка консалтинговых услуг - это большое количество видов и подвидов предоставляемых услуг. Услуги, которые предоставляют консалтинговые компании, можно классифицировать разными способами. В Европейском справочнике-указателе консультантов по управлению содержится такая классификация: общий менеджмент, администрирование и документооборот, финансовый менеджмент, управление персоналом, маркетинг, производственный менеджмент, IT-сфера, специализированный консалтинг (информационный, инженерный, юридический, экологический и т.д.) [10].

Потребителями перечисленных выше услуг являются компании и государственные структуры. Потребителей консалтинговых услуг можно сегментировать следующим образом.

Во-первых, по размеру компаний: мультинациональные компании, крупные корпорации, осуществляющие деятельность в одной конкретной стране, средние по размеру компании и малые фирмы. Как правило, консалтинговые компании выбирают целевую аудиторию, исходя из собственных размеров. Так, компании «большой четверки» ориентируются на первые две группы потребителей, в то время как небольшие фирмы и отдельные консультанты - на малый и средний бизнес. Как правило, размер компании прямо соотносится с уровнем сложности проблем, с которыми приходится иметь дело консультантам.

Во-вторых, по потребностям компаний. Если компания находится на начальных стадиях кризи$\mathrm{ca}$, то, как правило, она заинтересована в консультировании в области финансового менеджмента. Если компания собирается выходить на новый рынок, то обращается за маркетинговыми исследованиями.

В-третьих, по объему запрашиваемых услуг. Компании, которые обращаются за консалтинговыми услугами, могут заказывать как один определенный вид услуг (например, подбор персонала), так и целый комплекс услуг. Бывает часто, что компании передают целую функцию на аутсорсинг (например, тот же подбор персонала), что во многих случаях позволяет экономить на издержках и получать более качественные услуги. Таким образом, есть компании, которые прибегают к консалтингу время от времени, а есть те, которые используют консультантов на постоянной основе.

В-четверых, по искомым выгодам. Клиенты консалтинговых компаний по этому критерию делятся на три группы: те, кто стремится максимально сэкономить, т.е., для кого первостепенное значение имеет качество предоставляемых услуг, и те, кто стремится найти наилучшее соотношение между ценой и качеством. Это оказывает влияние на выбор поставщика консалтинговых услуг и на ход переговорного процесса.

В-пятых, по степени лояльности. Как и на большинстве других рынков, потребителей консалтинговых услуг можно разделить на лояльных одной фирме, лояльных группе компаний и не имеющих приверженности к какой-либо конкретной компании.

Согласно отчету компании Lexis Nexis за 2016 г., с точки зрения потребительского поведения мировой рынок консалтинговых услуг характеризуется следующими тенденциями развития. 
1. Привлечение нескольких консультантов. Данный тренд базируется на отказе от традиционного обслуживания одной компанией-консультантом в рамках большого проекта. Многие компании начинают все больше работать над привлечением узкоспециализированных специалистов для каждого отдельного этапа проекта. По мнению руководителей, специалисты, обладающие особыми знаниями в конкретных областях наиболее пригодны для работы на диверсифицированных проектах.

2. Борьба за персонал. В последние годы корпоративные расходы консалтинговых компаний не показывали значительных увеличений, в то время как индустриальный бизнес седьмой год подряд наращивает объем человеческого капитала, увеличивая расходы на персонал. Поскольку стратегия консалтинговых фирм нацелена на поиск и отбор самых талантливых сотрудников, данная тенденция может стать ключевой в настоящее время.

3. Внедрение современных технологий. Интеграция новых технологий становится все более масштабной и не обходит стороной даже такие отрасли, как консалтинг. При этом данная тенденция не несет в себе угрозы сокращений рабочих мест, преследуя цель объединения технологического анализа и человеческого капитала.

4. Ориентация на здравоохранительную отрасль. Отрасль здравоохранения сохраняет тенденцию вертикального развития и звание самой привлекательной отрасли. Данный сегмент оценивается в 175 млрд долл. США [10; 11]. Сильный рост сегмента здравоохранения способен значительно повлиять на увеличение консультационных проектов в этой сфере.

5. Формирование новых моделей консультирования. Данная тенденция базируется на возможностях и потребностях, появившихся благодаря информационной и технологической революциям. Например, компания под названием Wikistrat считает себя «первым в мире краудсорсинговым консультантом», с действующей глобальной сетью из более чем 2000 экспертов, работающих совместно через онлайн-платформу, чтобы помочь руководителям компаний определить решения сложных стратегических задач. Другая развивающаяся компания, HourlyNerd, создала краудсорсинговый рынок, который объединяет консультантов и бизнес-консультантов, чтобы помочь в существенном анализе и решении проблем.

\section{Библиографический список}

1. Блинов, А. О. Управленческое консультирование: учебник для магистров/ А. О. Блинов, В. А. Дресвянников. - М. : Дашков и К, 2013. -212 с.

2. Маринко, Г. И. Управленческий консалтинг : учеб. пособие / Г. И. Маринко. - М. : ИНФРА-М, 2005 - 381 с.

3. Посадский, А. П. Консультационные услуги в России : Практическое пособие для менеджеров и предпринимателей / А. П. Посадский, С. В. Хайниш. - М. : Финстатинформ, 2007. - 176 с.

4. Романов, А. А. Маркетинговые коммуникации / А. А. Романов, А. В. Панько. - М. :Эксмо, 2006. - 432 с.

5. Салтыков, В. А. Совершенствование организации управленческого консалтинга : монография / В. А. Салтыков. - Саарбрюккен : LAP LAMBERT Academic Publishing, 2013. - 108 c.

6. Скандальный аудитор Arthur Andersen намерен вернуться на рынок [Электронный ресурс] - Режим доступа : http://www.rbc.ru/economics/02/09/2014/570421919a794760d3d41255 (дата обращения : 12.09.2017).

7. EYGlobalreview 2016 [Электронный ресурс]. - Режим доступа :http://www.ey.com/gl/en/about-us/our-globalapproach/global-review/global-review-2016-facts-and-figures (дата обращения : 05.09.2017).

8. FEACO - Our objectives and activities [Электронный pecypc]- Режим доступа : http://www.feaco.org/aboutfeaco/objectives (дата обращения : 24.07.2017).

9. ICMCI - Global Consulting Community [Электронный ресурс]- Режим доступа: https://www.cmcglobal.org/content/global-consulting-community (дата обращения : 21.09.2017).

10. LexisNexis Predictions for the Consulting Industry in 2016 [Электронныйресурс]- Режимдоступа : https://www.lexisnexis.nl/_data/assets/pdf_file/0005/256352/Consulting-Industry-Report.pdf (датаобращения : 21.09.2017).

11. Size of Global Consulting Industry [Электронный pecypc].- Режим доступа : http://www.consultancy.uk/consulting-industry/global (дата обращения : 07.09.2017). 


\section{Reference}

1. Blinov A. O., Dresvyannikov V. A. Upravlencheskoe konsul'tirovanie [Management consulting]. Moscow, Dashkovi K ${ }^{\circ}, 2013.212$ p.

2. Marinko G. I. Upravlencheskij konsalting [Management consulting]. Moscow, INFRA-M, 2005. 381 p.

3. Posadskij A. P., Hajnish S. V. Konsul'tacionnye uslugi $v$ Rossii [Consulting services in Russia]. Moscow, Finstatinform, 2007. $176 \mathrm{p}$

4. Romanov A. A. Marketingovye kommunikacii [Marketing communications]. Moscow, Eksmo, 2006. 432 p.

5. Saltykov V. A. Sovershenstvovanie organizacii upravlencheskogo konsaltinga [Improving the organization of management consulting]. Saarbryukken, LAP LAMBERT Academic Publishing, 2013. 108 p.

6. Skandal'nyj auditor Arthur Andersen nameren vernut'sy anarynok [Scandalous auditor Arthur Andersen intends to return to the market]. Available at: http://www.rbc.ru/economics/02/09/2014/570421919a794760d3d41255 (Accessed: 12 September 2017).

7. EY Global review 2016. Available at: http://www.ey.com/gl/en/about-us/our-global-approach/global-review/globalreview-2016-facts-and-figures (Accessed: 05 September 2017).

8. FEACO - Our objectives and activities. Available at: http://www.feaco.org/aboutfeaco/objectives (Accessed: 24 July 2017).

9. ICMCI - Global Consulting Community. Available at: https://www.cmc-global.org/content/global-consultingcommunity (Accessed: 21 September 2017).

10. LexisNexis Predictions for the Consulting Industry in 2016 [Electronic source]. Available at: https://www.lexisnexis.nl/_data/assets/pdf_file/0005/256352/Consulting-Industry-Report.pdf (Accessed: 21 September 2017).

11. Size of Global Sonsulting Industry. Available at: http://www.consultancy.uk/consulting-industry/global (Accessed: 07 September 2017). 